\title{
Multipath for Agricultural and Rural Information Services in China
}

\author{
Ningning $\mathrm{Ge}^{1}$, Zhiyuan Zang $^{2}$, Lingwang Gao ${ }^{1, *}$, Qiang Shi ${ }^{2}$, \\ Jie $\mathrm{Li}^{3}$, Chunlin Xing ${ }^{2}$, and Zuorui Shen ${ }^{1}$ \\ ${ }^{1}$ IPMist Lab, College of Agriculture and Biotechnology, \\ China Agricultural University, Beijing, P.R. China, 100193, \\ Tel.: +86-10-62731884 \\ lwgao@cau.edu.cn \\ ${ }^{2}$ Beijing Candid soft Technology Co. Ltd. Beijing, P.R. China, 100083 \\ ${ }^{3}$ Plant Protection Institute, Shanxi Academy of Agricultural Sciences, \\ Taiyuan, Shanxi Province, P.R. China, 030031
}

\begin{abstract}
Internet cannot provide perfect information services for farmers in rural regions in China, because farmers in rural regions can hardly access the internet by now. But the wide coverage of mobile signal, telephone line, and television network, etc. gave us a chance to solve the problem. The integrated pest management platform of Northern fruit trees were developed based on the integrated technology, which can integrate the internet, mobile and fixed-line telephone network, and television network, to provide integrated pest management(IPM) information services for farmers in rural regions in E-mail, telephone-voice, short message, voice mail, videoconference or other format, to users' telephone, cell phone, personal computer, personal digital assistant(PDA), television, etc. alternatively. The architecture and the functions of the system were introduced in the paper. The system can manage the field monitoring data of agricultural pests, deal with enquiries to provide the necessary information to farmers accessing the interactive voice response(IVR) in the system with the experts on-line or off-line, and issue the early warnings about the fruit tree pests when it is necessary according to analysis on the monitoring data about the pests of fruit trees in variety of ways including SMS, fax, voice and intersystem e-mail.The system provides a platform and a new pattern for agricultural technology extension with a high coverage rate of agricultural technology in rural regions, and it can solve the problem of agriculture information service 'last kilometer' in China. The effectiveness of the system was certified.
\end{abstract}

Keywords: integrated technology, information services, agricultural and rural, multipathIntroduction.

\section{Introduction}

The use of ICT enables the production of goods in a short amount of time with the assistance of computerised systems. Services are also provided more efficiently and

* Corresponding author. 
rapidly (Bongo, P., 2005). Advances were made in promoting informatization of agriculture which is the key to speed up agricultural development in recent years in China. Agricultural and rural information service based on internet is developing rapidly, but the communication between the internet and farmers in rural regions is inefficient (Jiang Yongmei, et al., 2007; Michelle W, 2009) because most framers cannot afford the expenses for buying computers and accessing the Internet and they are not proficient in the skills of using the computer. It means that the farmers can hardly get the necessary information, include marketing information, extension advice, information about rural development programmes, and other information from government and private sources. So, the potential of information and communication technology (ICT) for the speedy dissemination of information to farmers need to be realised (Meera et al, 2004). Developing countries face challenges when harnessing ICTs potential for economic development(Michelle W. L. Fong, 2009). The method of integrating other information and telecommunication products such as television, mobile telephone, fixed-line telephone which have been popularized and have been brought into extensive application with the computer can improve the information services for farmers and provide interactive communication through the E-mail, telephone-voice(Lin Chuyou, et al., 2008), short message, voice mail, videoconference or other format anytime and anywhere.

Integrated technology refer to a new communication pattern that combined the computer technology and traditional communications technology or a platform which includes telecommunications networks, computer networks and cable television networks, achieveing the goal of offering the information service through multipath such as telephone, fax, data transmission, videoconference, call centers, real-time communication (http://www.skyoa.com). The user can connect the platform with many kinds of communication terminals and access any module in this platform to get the desired information, not limited to the only way of operating a computer.

Pests of fruit trees such as borers have caused great damage to the fruit growers (Myers, et al, 2006). Therefore it is necessary to investigate and research the biological characteristics, perniciousness feature, factors of influence, and prophylactic-therapeutic measures of the pest of fruit trees to reduce the loss. Moreover, it is more important to prvide information services to the farmers to control the pests damages.

The integrated pest management platform of fruit trees in Northern China were developed based on the integrated technology, which can integrate the internet, mobile and fixed-line telephone network, and television network, to provide integrated pest management(IPM) information services for farmers in rural regions in E-mail, telephone-voice, short message, voice mail, videoconference or other format, to users' telephone, cell phone, personal computer, personal digital assistant(PDA), television, etc. alternatively.

\section{Integrated Pest Management System of Fruit Trees in Northern China}

The integrated pest management platform of fruit trees in Northern China consists of four main parts by now: (1) Monitoring data acquisition and management System; (2) Expert response system based on the internet and telecommunications networks; (3) Information dissemination system; (4) Administration system of agricultural production. 


\subsection{Monitoring Data Acquisition and Management System}

The system of monitoring data acquisition based on PDA and GPS is developed by visual studio with three functions: collecting data, processing data, and output. PDA receives the signals of GPS through internal or external GPS hardware devices. Binding the manual input data about the dynamic of the fruit tree, the environment and the pests with latitude and longitude information, PDA stores all data in XML document which can be transferred using wireless transmission into the remote database. This can significantly improve the efficiency and guarantee accuracy of the data comparing with the traditional methodes of data acquisition which write the data on the paper before input them into the computer(Wu Shou-zhong et al, 2005).

Environmental parameters, such as illumination, temperature, humidity can be recorded with the sensor devices which can be set the time interval and automatically send to the remote database through the GPRS network.

Beside the data come from PDA and sensor device, the user also can input the historical data into the database through the interface based on the computer and manage them.

\subsection{Expert Response System}

An expert database was set up in the system which contain related expert s' information, such as address, contact details, academic field on which response the

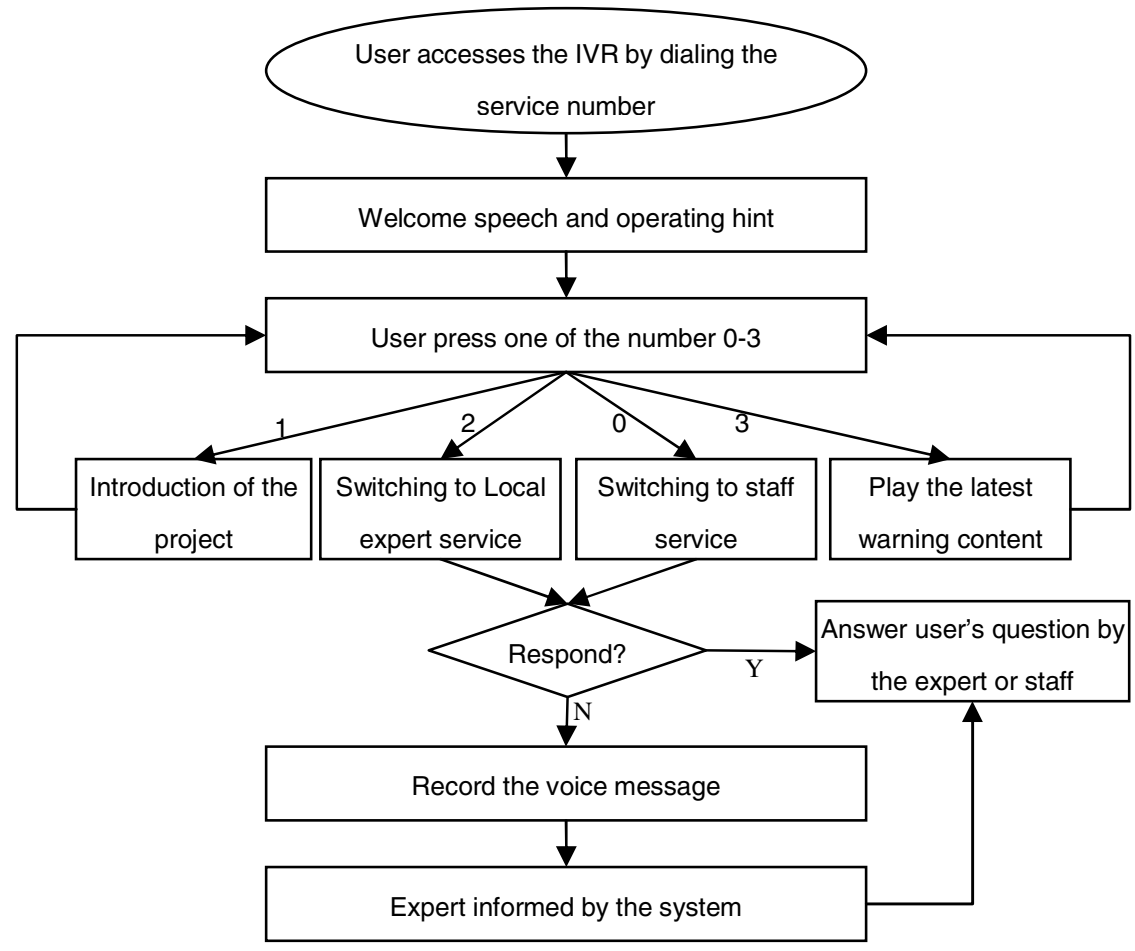

Fig. 1. Tthe flowchart IVR in the system 
consultation service. The system automatically assigns the expert to the consultant who dials the service number and access the interactive voice response (IVR) in the system on the basis of dialing area code; the expert can answer the questions including diagnosis of pest, market information, prevention and control measures from the consultant. If the assigned expert have no time to answer the phone, the consultant can leave a voice message which would be recorded in the system and sent to the expert electronic mailbox in the system as a .wav format file. When it is possibel, the expert can call back or leave a voice message in the system to answer the consultant's questions. Beside making a call, the consultants also can send Short Messaging Service(SMS) and Multimedia Message Service (MMS) with picture and video about the pest or symptom damaged by the pest to the system using cell phone. The system can record the ask-answer process in a process tracking database. When the process ends, the expert collates the questions and answers, adding them into the database of questions and answers to enrich the information contents that can reduce the expert future work. In addition, entering some common knowledge the fruit grower need at earlier time helps the intelligent retrieval (Dong Xiaoxia, et al, 2009).

\subsection{Information Dissemination System}

Agency in charge of the project issues the early warnings about the fruit tree pests when it is necessary according to analysis on the monitoring data about the insect pest of fruit trees. The early warnings can be sent in variety of ways including SMS, fax, voice and intersystem e-mail. A message can accommodate 44 characters, the excess words will be send in another one. The system supports the tif (for fax) and .wav (for phones and voice mail) format file comes from local-storage, and the voice can come from online recoding by phones also. Fig2 shows the flowchart of early warning Information dissemination, and Fig 3 shows the interface of early warning information dissemination.

The administrator of the system is able to view the efficiency of broadcasting of the early warnings through the statistics function which reveals the percentage of respond to the warning. The system can automatically send the information again to the un-responded users in certain interval before the deadline in order to ensure that every fruit grower has received the information to avoid serious damages.

\subsection{Administration of Agricultural Production}

The administrator creates a staff tree according the titles, positions and research backgrounds, and assigns different rights to the persons on this tree in order to be responsible for different work. At the mean time the system also allocates every staff a extension telephone number which can be set feature service by oneself. The persons on this tree can connect with the system by MMS, mobile phone, fixed-line telephone, intenet etc. and deal with the business about the agricultural production in time without missing any important task. Furthermore, they also can query or browse the data in the database by inputting simple instructions.

\section{Discussion}

Integrated pest management system of fruit trees in Northern China, a platform based on the integrated technology, enables the fruit growers in rural region, experts, the 
agricultural officers to easily access to the system via the variety of device, such as PDA, cell phone, fixed-line telephone and the computer. This would change the situation that most information system involving agriculture cannot provide the efficiency information services to the farmer in rural region. The system provides a platform and a new pattern for agricultural technology extension with a high coverage rate of agricultural technology in rural regions, and it can solve the problem of agriculture information service 'last kilometer' in China.

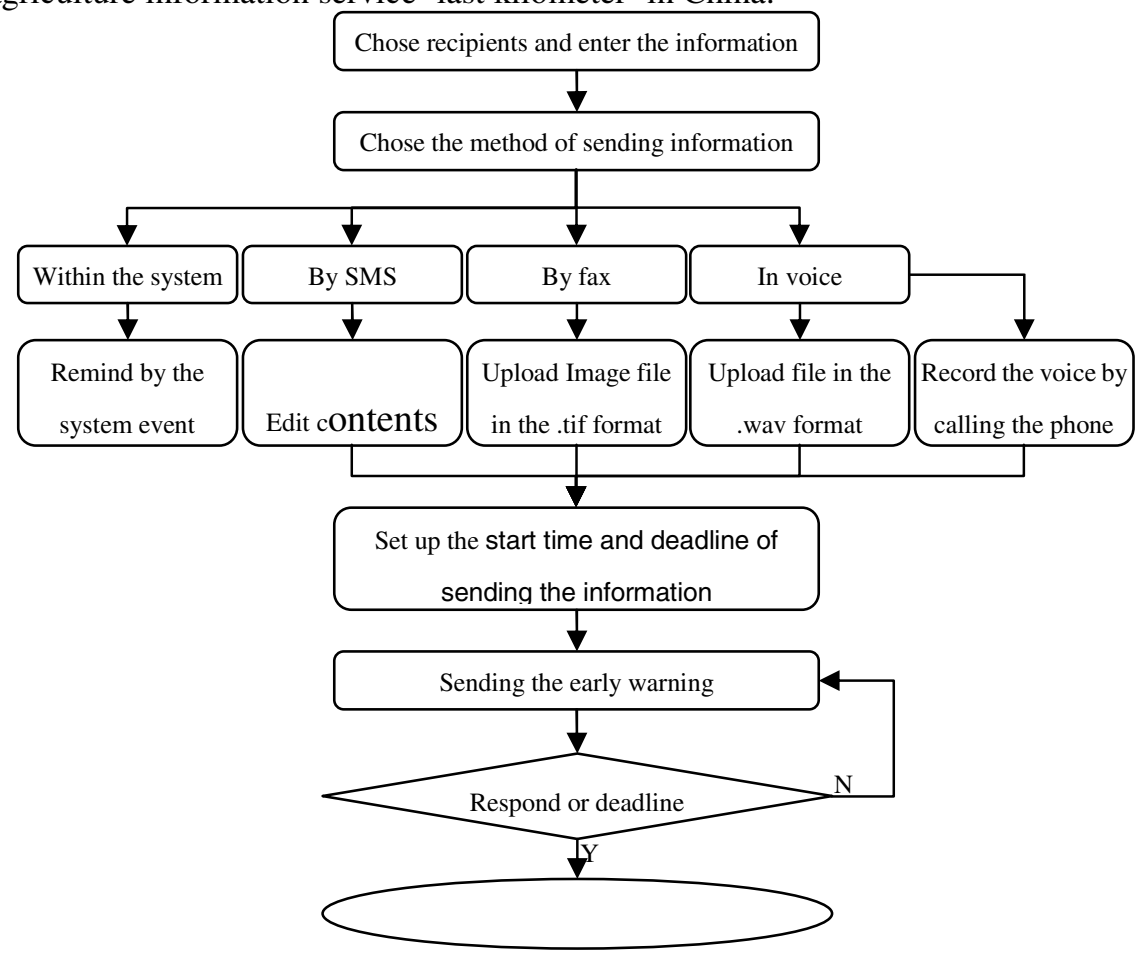

Fig. 2. The flowchart of early warning information dissemination

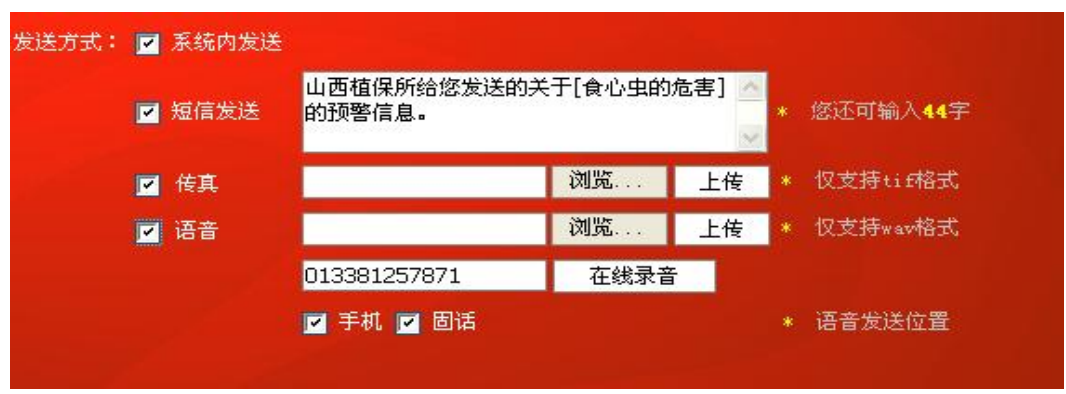

Fig. 3. The interface of early warning information dissemination system 
The system is still in expanding and it would be a robust, reliable, and expandable integrated pest management information system in the future. Scalable architectural design facilitates the addition of a wide variety of new functions. Main current limitations of the system is the data analysis which depends on the data collection by investigator in the later practice, and it needs developing more functional sub-systems, such as an expert system for forecast and prediction of pests (Gao Lingwang, et al.,2006; Liu Minghui, et al, 2009), a pest spatial analysis information system based on WebGIS and remote sensing (Gong Yanping, et al., 2008), and a remote diagnosis system based on technologies of image processing (Yang Hongzhen, et al.,2008), expert system(Prasad, et al, 2006; Lingwang Gao, 2009), and video conferencing system (Liu Yuexian, et al., 2002).

Additionally, the system can also be expanded to providing the information of the agricultural production technology, market, and whatever farmers need except the IPM information.

\section{Acknowledgements}

This research was supported by Public Welfare Project from Ministry of Agriculture of the People's Republic of China (Grant No: 200803006).

\section{References}

Bongo, P.: The impact of ICT on economic growth (2005),

http://129.3.20.41/eps/dev/papers/0501/0501008.pdf

(Retrieved November 30, 2007)

Xiaoxia, D., Guifa, T., Fang, W., et al.: The Ontology - based Agricultural Information Service System. Journal of Agricultural Mechanization Research (6), 137-140 (2009)

Lingwang, G., Jiguang, C., Xinwen, Y., et al.: Research and development of the expert system platform for forecast and prediction of agricultural pests. Transactions of the CSAE 22(10), 154-158 (2006)

Gao, L., Yan, C., Shen, Z.: Designing and Algorithm Implementing of the Expert System Platform for Assistant Identification of Agricultural Pests Based on a Dendriform Hierarchical Structure. In: Proceedings of 2009 World Congress on Software Engineering, WCSE 2009, Xiamen, China, May 19-21, pp. 205-210 (2009)

Yanping, G., Wenjiang, H., Yuchun, P., et al.: Construction of a Web GIS-based forecast system of crop diseases and pests. Journal of Natural Diastase 17(6), 36-41 (2008)

Integrated technology,

http://www.skyoa.com/phpcms/rhsy/2008/0723/article_12.html

Yongmei, J., Yaohui, X., Ping, G., et al.: Thought of present situation of agricultural information service system in villages and towns. Agriculture Network Information (1), 44-57 (2007)

Chuyou, L., Yanyong, X.: Application of intelligent telephone phonetic system in agriculture information service. Agriculture Network Information (3), 39-40 (2008)

Minghui, L., Zuorui, S., Lingwang, G., et al.: Expert System Based on WebGIS for Forecast and Prediction of Agricultural Pests. Transactions of the Chinese Society for Agricultural Machinery 40(07), 180-186 (2009) 
Yuexian, L., Zuorul, S., Xinyan, C., et al.: Development of the computer-aided species identification and information service system for agricultural pests management. Computer and Agriculture (1), 9-11 (2002)

Meera, S.N., Jhamtani, Q., Rao, D.U.M.: Information and communication technology in agrudultural development: Acomparative analysis of three projects from india. ODI: Agrudultural Research \& Extension Network, Network paper No. 135 (2004)

Fong, M.W.L.: Digital Divide: The Case of Developing Countries. Issues in Informing Science and Information Technology (6), 471-478 (2009)

Myers, C.T., Hull, L.A., Krawczyk, G.: Comparative survival rates of oriental fruit moth (Lepidoptera: Tortricidae) larvae on shoots and fruit of apple and peach. J. Econ. Entomol. 99(4), 1299-1309 (2006)

Prasad, R., Ranjan, K.R., Sinha, A.K.: AMRAPALIKA: An expert system for the diagnosis of pests, diseases, and disorders in Indian mango. Knowledge-Based Systems 19(1), 9-21 (2006)

Shou-zhong, W., Ling-wang, G., Da-zhao, S., et al.: Development Data Collection System of the Rodent Pest on the Grassland Based on the PDA with GPS. Acta Agrestia Sinica 15(6), 550-555 (2007)

Mahajan, S.: Impact of Digital Divide on Developing Countries with Special Reference to India. SERALS Journal of Information Management 40(4), 328-329 (2003)

Hongzhen, Y., Jianwei, Z., Xiangtao, L., et al.: Remote automatic identification system based on insect image. Transactions of the CSAE 24(1), 188-192 (2008) 